\title{
3. Comercio exterior de mercancías por sectores económicos
}


3.1. COMERCIO EXTERIOR DE MERCANCÍAS. EXPORTACIONES DESGLOSE POR SECTORES ECONÓMICOS

(Millones de euros)

\begin{tabular}{|c|c|c|c|c|c|c|c|c|}
\hline & 2010 & 2011 & 2012 & 2013 & 2014 & 2015 & 2016 & $2017^{*}$ \\
\hline 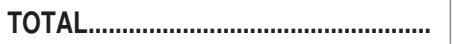 & $186.780,1$ & $215.230,4$ & $226.114,6$ & $235.814,1$ & $240.581,8$ & $249.794,4$ & $256.393,4$ & $277.125,7$ \\
\hline Alimentación, bebidas y tabaco......... & $28.098,0$ & $31.063,8$ & $34.334,2$ & $35.846,4$ & $37.327,5$ & $40.616,7$ & $43.116,7$ & $45.775,3$ \\
\hline Productos cárnicos .............................. & $3.482,9$ & $4.122,0$ & $4.654,8$ & $4.734,1$ & $5.058,1$ & $5.659,2$ & $6.359,3$ & $7.017,2$ \\
\hline Productos pesqueros.......................... & $2.455,0$ & $2.942,4$ & $2.942,5$ & $2.887,7$ & $2.924,5$ & $3.242,8$ & $3.557,3$ & $3.988,0$ \\
\hline Frutas, hortalizas y legumbres ........... & $11.472,8$ & $11.857,1$ & $13.187,1$ & $14.204,2$ & $14.497,0$ & $16.351,8$ & $16.887,6$ & $17.245,4$ \\
\hline Lácteos y huevos..................................... & $1.005,9$ & $1.035,2$ & $1.078,8$ & $1.121,7$ & $1.217,9$ & $1.289,1$ & $1.263,1$ & $1.449,4$ \\
\hline Cereales ......................................... & 407,5 & 513,4 & 459,9 & 543,8 & 479,7 & 497,9 & 449,7 & 469,0 \\
\hline Azúcar, café y cacao ............................ & $1.183,9$ & $1.367,1$ & $1.387,5$ & $1.331,8$ & $1.420,0$ & $1.595,5$ & $1.696,4$ & $1.720,1$ \\
\hline Preparados alimenticios .................... & $1.935,3$ & $2.179,8$ & $2.443,2$ & $2.653,2$ & $2.802,3$ & $2.977,3$ & $3.228,3$ & $3.366,1$ \\
\hline Grasas y aceites................................. & $2.513,7$ & $2.781,3$ & $3.224,3$ & $3.160,3$ & $3.756,8$ & $3.618,1$ & $4.256,7$ & $4.895,5$ \\
\hline Semillas y frutos oleaginosos ................ & 71,9 & 87,4 & 81,3 & 107,0 & 124,1 & 139,6 & 174,1 & 156,7 \\
\hline 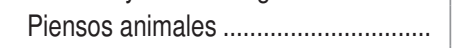 & 729,6 & 873,4 & $1.166,4$ & $1.125,0$ & $1.100,7$ & $1.199,9$ & $1.192,1$ & $1.208,6$ \\
\hline Bebidas....... & $2.595,8$ & $3.015,9$ & $3.389,2$ & $3.672,2$ & $3.610,6$ & $3.789,1$ & $3.805,6$ & $4.015,3$ \\
\hline 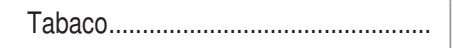 & 243,7 & 288,6 & 319,2 & 305,4 & 336,0 & 256,3 & 246,2 & 244,1 \\
\hline Productos energéticos.............................. & $9.641,1$ & $13.497,2$ & $17.144,2$ & $16.339,1$ & $17.663,0$ & $12.608,9$ & $13.799,1$ & $19.611,2$ \\
\hline Petróleo y derivados............................... & $8.866,7$ & $12.376,4$ & $15.365,7$ & $14.114,3$ & $14.554,1$ & $11.111,5$ & $12.892,3$ & $18.153,0$ \\
\hline Gas ..................................... & 188,1 & 386,5 & 859,6 & $1.540,4$ & $2.405,5$ & 692,5 & 312,9 & 499,9 \\
\hline Carbón............................. & 220,6 & 263,0 & 320,2 & 135,5 & 162,1 & 145,2 & 89,6 & 76,8 \\
\hline Corriente eléctrica ............... & 365,7 & 471,3 & 598,8 & 549,0 & 541,3 & 659,7 & 504,3 & 881,5 \\
\hline Materias primas ...................................... & $4.490,6$ & $5.883,1$ & $6.014,3$ & $6.057,1$ & $5.720,4$ & $5.528,8$ & $5.224,0$ & $7.141,8$ \\
\hline Animales y vegetales........................... & $2.120,4$ & $2.494,2$ & $2.719,1$ & $2.780,7$ & $2.617,6$ & $2.335,9$ & $2.461,9$ & $2.754,8$ \\
\hline Minerales ........................................... & $2.370,1$ & $3.388,9$ & $3.295,1$ & $3.276,4$ & $3.102,7$ & $3.192,9$ & $2.762,1$ & $4.387,0$ \\
\hline Semimanufacturas no químicas ........ & $22.651,5$ & $25.801,9$ & $25.826,4$ & $25.237,3$ & $25.641,3$ & $26.115,6$ & $25.561,3$ & $28.067,8$ \\
\hline Metales no ferrosos .............................. & $4.092,8$ & $4.789,5$ & $5.085,5$ & $4.629,7$ & $4.881,8$ & $5.206,0$ & $5.188,2$ & $6.264,6$ \\
\hline Hierro y acero .................................... & $7.794,6$ & $9.110,6$ & $8.696,4$ & $8.214,6$ & $8.213,4$ & $7.700,6$ & $6.911,2$ & $7.789,7$ \\
\hline 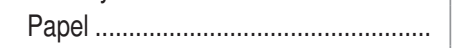 & $3.213,6$ & $3.340,3$ & $3.355,5$ & $3.399,2$ & $3.320,8$ & $3.460,4$ & $3.464,0$ & $3.552,6$ \\
\hline Productos cerámicos y similares ......... & $2.486,9$ & $2.699,4$ & $2.904,4$ & $3.133,7$ & $3.326,9$ & $3.611,1$ & $3.800,6$ & $4.117,2$ \\
\hline Cal y cemento .................................... & 827,1 & 873,2 & 989,8 & $1.054,0$ & $1.150,7$ & $1.174,1$ & $1.155,9$ & $1.080,6$ \\
\hline 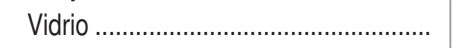 & 550,8 & 613,6 & 573,7 & 588,1 & 636,6 & 704,3 & 761,6 & 742,2 \\
\hline Neumáticos y cámaras ........................ & $1.857,7$ & $2.287,7$ & $2.209,7$ & $2.176,5$ & $2.018,1$ & $1.940,5$ & $1.915,1$ & $1.962,2$ \\
\hline Resto de otras semimanufacturas...... & $1.827,9$ & $2.087,6$ & $2.011,4$ & $2.041,6$ & $2.093,0$ & $2.318,6$ & $2.364,8$ & $2.558,8$ \\
\hline Productos químicos............................. & $28.274,2$ & $30.244,7$ & $32.192,8$ & $33.270,3$ & $34.200,9$ & $36.031,2$ & $36.037,7$ & $38.823,9$ \\
\hline Productos químicos orgánicos ........... & $3.479,8$ & $3.223,8$ & $3.326,2$ & $3.389,1$ & $3.573,4$ & $3.573,1$ & $3.376,0$ & $3.691,3$ \\
\hline Productos químicos inorgánicos.......... & 700,5 & 831,2 & 867,6 & 955,7 & 920,7 & 981,0 & 995,9 & 999,5 \\
\hline Medicamentos .................................. & $8.881,8$ & $9.791,3$ & $10.482,8$ & $10.421,4$ & $10.200,9$ & $10.874,7$ & $10.436,1$ & $10.667,3$ \\
\hline Plásticos ......................................... & $7.389,1$ & $8.143,9$ & $8.318,8$ & $8.638,6$ & $9.357,7$ & $9.762,0$ & $9.734,6$ & $10.688,8$ \\
\hline 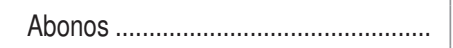 & 607,0 & 642,3 & 777,1 & 749,9 & 677,3 & 738,5 & 694,6 & 752,2 \\
\hline Colarantes y curtientes.......................... & $1.689,0$ & $1.838,1$ & $2.011,5$ & $2.121,7$ & $2.198,9$ & $2.316,5$ & $2.333,0$ & $2.565,4$ \\
\hline Aceites esenciales y perfumados....... & $3.112,5$ & $3.328,3$ & $3.510,4$ & $3.897,3$ & $4.125,8$ & $4.380,2$ & $4.557,5$ & $5.053,6$ \\
\hline Otros productos químicos..................... & $2.414,5$ & $2.445,8$ & $2.898,4$ & $3.096,7$ & $3.146,1$ & $3.405,2$ & $3.910,1$ & $4.405,6$ \\
\hline Bienes de equipo.................................... & $37.770,1$ & $43.875,6$ & $44.129,3$ & $49.528,7$ & $48.465,4$ & $49.981,0$ & $53.147,6$ & $56.344,0$ \\
\hline Maquinaria agrícola ........................... & 385,8 & 452,1 & 506,5 & 445,6 & 441,2 & 437,6 & 456,5 & 478,1 \\
\hline Maquinaria de obras públicas.............. & 375,3 & 588,8 & 757,3 & $1.530,3$ & 456,0 & 750,9 & 403,1 & 542,5 \\
\hline Maquinaria textil .................................. & 216,1 & 275,9 & 267,1 & 298,4 & 306,5 & 348,1 & 331,7 & 315,9 \\
\hline Maquinaria para trabajar metal........... & 853,0 & $1.088,8$ & $1.210,9$ & $1.318,1$ & $1.186,5$ & $1.220,9$ & $1.272,6$ & $1.374,5$ \\
\hline Otra maquinaria específica................... & $1.539,2$ & $1.647,3$ & $1.834,1$ & $2.105,7$ & $1.997,8$ & $2.031,6$ & $2.068,5$ & $2.168,9$ \\
\hline Maquinaria de uso general ................. & $6.376,6$ & $7.135,3$ & $7.900,6$ & $8.411,9$ & $8.372,9$ & $8.626,5$ & $8.753,2$ & $9.394,6$ \\
\hline
\end{tabular}




\subsection{COMERCIO EXTERIOR DE MERCANCÍAS. EXPORTACIONES (continuación)} DESGLOSE POR SECTORES ECONÓMICOS

(Millones de euros)

\begin{tabular}{|c|c|c|c|c|c|c|c|c|}
\hline & 2010 & 2011 & 2012 & 2013 & 2014 & 2015 & 2016 & $2017^{*}$ \\
\hline Equipos de oficina .......... & 200,6 & 220,9 & 260,6 & 279,2 & 260,9 & 283,6 & 318,3 & 310,4 \\
\hline Maquinaria de automatización de datos.............. & 653,9 & 713,5 & 630,2 & 666,9 & 718,5 & 694,9 & 704,9 & 974,7 \\
\hline 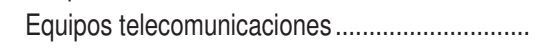 & $2.370,2$ & $1.994,8$ & $1.573,7$ & $1.348,1$ & $1.527,8$ & $1.774,3$ & $1.791,0$ & $1.821,8$ \\
\hline 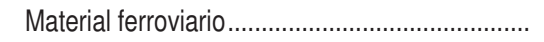 & 668,8 & $1.054,9$ & $1.288,8$ & $1.053,6$ & $1.524,6$ & $1.095,5$ & $1.148,8$ & $1.423,2$ \\
\hline Vehic. Trans. mercancías carretera .................... & $4.294,0$ & $5.325,5$ & $4.727,6$ & $5.692,9$ & $6.149,1$ & $5.718,6$ & $6.917,7$ & $7.058,8$ \\
\hline Buques & $1.524,0$ & $1.389,7$ & 685,2 & $1.044,8$ & 822,4 & 695,3 & 609,4 & 890,6 \\
\hline Aeronaves & $2.693,2$ & $3.300,4$ & $3.420,7$ & $5.304,9$ & $4.039,9$ & $3.985,7$ & $6.176,8$ & $5.752,8$ \\
\hline 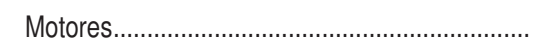 & $1.115,5$ & $1.601,3$ & $1.609,1$ & $1.675,0$ & $1.607,5$ & $1.781,4$ & $1.823,9$ & $2.376,5$ \\
\hline Aparatos eléctricos & $7.933,3$ & $9.712,6$ & $9.883,4$ & $10.139,0$ & $10.351,9$ & $11.086,5$ & $10.890,5$ & $11.386,0$ \\
\hline Aparatos de precisión & $1.267,5$ & $1.400,8$ & $1.507,7$ & $1.558,7$ & $1.833,4$ & $2.028,1$ & $2.213,9$ & $2.224,4$ \\
\hline Resto bienes de equipo & $5.303,2$ & $5.973,1$ & $6.065,9$ & $6.655,6$ & $6.868,3$ & $7.421,6$ & $7.266,8$ & $7.850,2$ \\
\hline 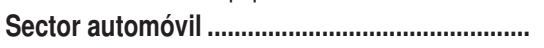 & $29.921,8$ & $33.301,3$ & $30.788,3$ & $33.396,9$ & $35.547,8$ & $42.739,6$ & $45.275,2$ & $45.175,8$ \\
\hline 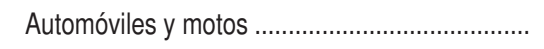 & $20.200,4$ & $22.568,5$ & $20.153,3$ & $22.481,5$ & $24.302,4$ & $30.352,2$ & $32.728,3$ & $32.224,3$ \\
\hline Componentes del automóvil ............................... & $9.721,3$ & $10.732,8$ & $10.635,0$ & $10.915,4$ & $11.245,4$ & $12.387,4$ & $12.546,8$ & $12.951,6$ \\
\hline 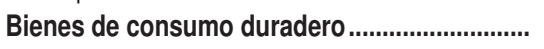 & $3.597,9$ & $3.702,0$ & $3.577,1$ & $3.544,6$ & $3.375,9$ & $4.012,1$ & $4.363,6$ & $4.481,0$ \\
\hline Electrodomésticos ............................................ & 807,8 & $1.161,8$ & $1.169,2$ & $1.156,3$ & 931,9 & $1.205,0$ & $1.202,1$ & $1.285,0$ \\
\hline Electrónica de consumo & $1.003,4$ & 636,2 & 503,7 & 313,8 & 307,0 & 430,7 & 538,2 & 482,5 \\
\hline Muebles & $1.349,1$ & $1.402,3$ & $1.427,2$ & $1.597,7$ & $1.676,5$ & $1.872,0$ & $2.079,4$ & $2.113,3$ \\
\hline 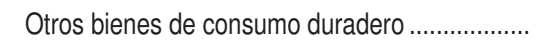 & 437,7 & 501,6 & 477,1 & 476,8 & 460,5 & 504,5 & 543,9 & 600,2 \\
\hline 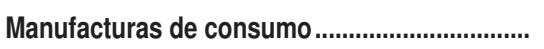 & $16.035,1$ & $18.185,2$ & $19.158,8$ & $20.724,5$ & $22.090,1$ & $23.719,5$ & $25.625,7$ & $28.196,3$ \\
\hline Confección & $5.842,1$ & $6.862,5$ & $7.711,2$ & $8.672,4$ & $9.368,1$ & $10.557,9$ & $11.521,0$ & $12.636,3$ \\
\hline 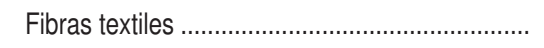 & 120,5 & 159,4 & 173,0 & 187,5 & 184,5 & 172,9 & 207,9 & 306,6 \\
\hline 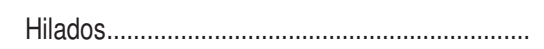 & 446,9 & 498,6 & 460,0 & 480,4 & 468,6 & 454,7 & 439,3 & 482,2 \\
\hline Tejidos ......................... & $1.406,8$ & $1.488,2$ & $1.506,8$ & $1.588,3$ & $1.656,2$ & $1.677,8$ & $1.827,5$ & $1.903,9$ \\
\hline Resto de textiles & $1.025,5$ & $1.100,3$ & $1.144,5$ & $1.195,6$ & $1.284,6$ & $1.369,4$ & $1.452,4$ & $1.608,1$ \\
\hline Calzado & $1.958,3$ & $2.184,2$ & $2.184,4$ & $2.376,9$ & $2.753,1$ & $2.645,9$ & $2.739,5$ & $2.826,5$ \\
\hline Juguetes ....................... & 689,4 & 901,2 & 700,4 & 761,8 & 813,6 & 915,6 & $1.154,7$ & $1.661,5$ \\
\hline Alfarería & 90,9 & 87,5 & 85,7 & 89,9 & 85,9 & 96,9 & 147,9 & 102,7 \\
\hline Joyería y relojes ............................................... & 641,6 & 862,4 & 992,0 & 891,3 & 829,7 & 937,3 & 897,9 & 867,9 \\
\hline 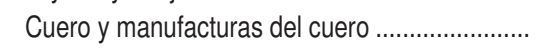 & 448,9 & 532,2 & 543,2 & 558,8 & 589,2 & 556,1 & 551,1 & 573,3 \\
\hline Resto de otras manufacturas de consumo......... & $3.364,4$ & $3.508,8$ & $3.657,6$ & $3.921,5$ & $4.056,5$ & $4.335,3$ & $4.686,4$ & $5.227,3$ \\
\hline Otras mercancías & $6.299,9$ & $9.675,6$ & $12.949,1$ & $11.869,1$ & $10.549,6$ & $8.440,9$ & $4.242,5$ & $3.508,5$ \\
\hline
\end{tabular}




\subsection{COMERCIO EXTERIOR DE MERCANCÍAS. IMPORTACIONES DESGLOSE POR SECTORES ECONÓMICOS}

(Millones de euros)

\begin{tabular}{|c|c|c|c|c|c|c|c|c|}
\hline & 2010 & 2011 & 2012 & 2013 & 2014 & 2015 & 2016 & $2017^{*}$ \\
\hline TOTAL_................................................... & $240.055,9$ & $263.140,7$ & $257.945,6$ & $252.346,8$ & $265.556,6$ & $274.772,3$ & $273.778,6$ & $301.870,1$ \\
\hline Alimentación, bebidas y tabaco......... & $24.954,1$ & $27.452,6$ & $28.267,7$ & $27.865,1$ & $28.647,2$ & $31.221,0$ & $32.238,4$ & $34.647,9$ \\
\hline Productos cárnicos .............................. & $1.681,9$ & $1.779,4$ & $1.768,3$ & $1.820,7$ & $1.899,9$ & $2.030,4$ & $2.048,3$ & $2.229,8$ \\
\hline Productos pesqueros.......................... & $4.868,4$ & $5.184,3$ & $4.869,3$ & $4.769,7$ & $5.181,2$ & $5.732,7$ & $6.344,4$ & $6.962,2$ \\
\hline Frutas, hortalizas y legumbres ........... & $3.214,1$ & $3.366,2$ & $3.486,4$ & $3.820,3$ & $3.992,8$ & $4.683,7$ & $5.121,9$ & $5.315,2$ \\
\hline Lácteos y huevos.... & $1.859,8$ & $1.918,4$ & $1.926,7$ & $1.968,2$ & $1.970,6$ & $1.789,2$ & $1.752,6$ & $1.937,5$ \\
\hline Cereales & $1.888,4$ & $2.549,2$ & $3.074,2$ & $2.412,5$ & $2.531,9$ & $2.835,7$ & $2.740,3$ & $2.879,1$ \\
\hline Azúcar, café y cacao ............................ & $2.258,8$ & $3.031,5$ & $2.818,4$ & $2.823,7$ & $2.817,7$ & $2.913,1$ & $2.998,9$ & $3.126,5$ \\
\hline Preparados alimenticios .................... & $2.216,3$ & $2.235,8$ & $2.209,6$ & $2.119,7$ & $2.050,4$ & $2.187,1$ & $2.369,0$ & $2.470,6$ \\
\hline Grasas y aceites................. & $1.225,3$ & $1.420,2$ & $1.435,0$ & $1.718,0$ & $1.721,5$ & $2.211,0$ & $2.305,7$ & $2.938,8$ \\
\hline Semillas y frutos oleaginosos ................ & $1.380,5$ & $1.591,0$ & $1.935,4$ & $1.804,4$ & $1.793,4$ & $1.752,8$ & $1.565,7$ & $1.633,4$ \\
\hline Piensos animales & $1.295,3$ & $1.375,3$ & $1.608,9$ & $1.531,5$ & $1.687,4$ & $1.833,4$ & $1.720,7$ & $1.751,1$ \\
\hline Bebidas....... & $1.614,5$ & $1.730,8$ & $1.717,0$ & $1.689,6$ & $1.641,6$ & $1.737,4$ & $1.798,7$ & $1.785,4$ \\
\hline 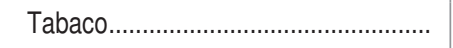 & $1.450,8$ & $1.270,5$ & $1.418,4$ & $1.386,9$ & $1.358,9$ & $1.514,4$ & $1.472,1$ & $1.618,3$ \\
\hline Productos energéticos.............................. & $44.082,5$ & $56.397,3$ & $62.190,1$ & $57.332,4$ & $54.503,6$ & $38.443,4$ & $30.430,7$ & $40.332,4$ \\
\hline Petróleo y derivados............................... & $34.394,3$ & $44.306,0$ & $48.686,1$ & $45.200,4$ & $42.388,4$ & $28.843,2$ & $22.667,8$ & $30.326,5$ \\
\hline Gas .......................... & $8.314,5$ & $10.146,8$ & $11.356,1$ & $10.738,6$ & $10.625,3$ & $7.842,0$ & $6.055,0$ & $7.014,5$ \\
\hline Carbón............................. & $1.232,9$ & $1.795,3$ & $1.937,1$ & $1.117,3$ & $1.155,0$ & $1.271,0$ & 864,8 & $1.741,8$ \\
\hline Corriente eléctrica ............. & 140,8 & 149,2 & 210,8 & 276,1 & 334,9 & 487,3 & 843,1 & $1.249,5$ \\
\hline Materias primas ...................................... & $9.250,8$ & $11.089,9$ & $10.042,2$ & $9.540,0$ & $9.375,0$ & $9.202,8$ & $8.670,0$ & $10.786,1$ \\
\hline Animales y vegetales........................... & $2.939,8$ & $3.496,7$ & $3.094,3$ & $2.960,5$ & $2.755,1$ & $2.935,2$ & $2.930,3$ & $3.170,4$ \\
\hline 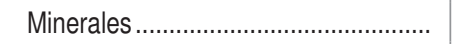 & $6.310,9$ & $7.593,2$ & $6.947,8$ & $6.579,5$ & $6.619,8$ & $6.267,6$ & $5.739,7$ & $7.615,7$ \\
\hline Semimanufacturas no químicas ........ & $17.919,4$ & $19.982,9$ & $17.574,9$ & $17.137,9$ & $17.983,6$ & $18.827,9$ & $18.731,5$ & $21.511,3$ \\
\hline Metales no ferrosos .............................. & $3.203,8$ & $3.685,6$ & $3.150,8$ & $3.179,4$ & $3.193,1$ & $3.528,1$ & $3.636,0$ & $4.372,6$ \\
\hline Hierro y acero ....................................... & $6.947,9$ & $8.105,9$ & $6.896,3$ & $6.473,7$ & $6.863,8$ & $6.921,5$ & $6.437,8$ & $8.117,8$ \\
\hline 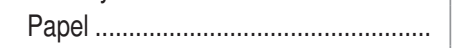 & $3.320,6$ & $3.506,2$ & $3.284,6$ & $3.281,1$ & $3.415,1$ & $3.484,3$ & $3.457,4$ & $3.566,7$ \\
\hline Productos cerámicos y similares ......... & 569,6 & 572,2 & 502,7 & 508,3 & 584,1 & 643,8 & 775,0 & 815,8 \\
\hline Cal y cemento .................................... & 232,4 & 151,3 & 123,0 & 107,5 & 133,6 & 130,3 & 133,9 & 147,6 \\
\hline Vidrio & 550,7 & 610,2 & 456,9 & 436,7 & 499,9 & 614,8 & 661,1 & 704,0 \\
\hline Neumáticos y cámaras ........................ & $1.353,2$ & $1.457,5$ & $1.430,2$ & $1.511,1$ & $1.516,9$ & $1.574,6$ & $1.561,1$ & $1.604,5$ \\
\hline Resto de otras semimanufacturas....... & $1.741,3$ & $1.894,0$ & $1.730,6$ & $1.640,1$ & $1.776,9$ & $1.930,6$ & $2.069,2$ & $2.182,4$ \\
\hline Productos químicos............................. & $36.545,4$ & $38.836,2$ & $38.818,7$ & $38.797,1$ & $40.396,9$ & $43.713,6$ & $42.617,4$ & $44.936,6$ \\
\hline Productos químicos orgánicos ............ & $7.247,9$ & $7.799,2$ & $7.787,8$ & $8.167,9$ & $8.316,5$ & $8.227,9$ & $7.888,8$ & $8.563,8$ \\
\hline Productos químicos inorgánicos.......... & $1.775,4$ & $1.974,5$ & $2.115,9$ & $1.992,3$ & $1.920,6$ & $2.016,6$ & $1.770,7$ & $1.910,7$ \\
\hline Medicamentos ...................................... & $11.493,0$ & $11.618,9$ & $11.794,6$ & $11.435,4$ & $12.074,7$ & $13.826,2$ & $13.201,3$ & $13.019,7$ \\
\hline Plásticos ............................................ & $7.475,1$ & $7.824,0$ & $7.543,5$ & $7.916,6$ & $8.578,2$ & $9.463,8$ & $9.485,2$ & $10.373,2$ \\
\hline 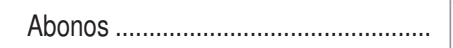 & 582,3 & 709,5 & 804,3 & 902,7 & 999,9 & $1.093,3$ & 780,9 & 865,8 \\
\hline Colarantes y curtientes.......................... & $1.248,0$ & $1.363,3$ & $1.259,9$ & $1.294,6$ & $1.463,2$ & $1.475,8$ & $1.551,5$ & $1.803,9$ \\
\hline Aceites esenciales y perfumados....... & $2.708,7$ & $2.785,8$ & $2.803,7$ & $3.047,8$ & $3.219,2$ & $3.481,3$ & $3.675,1$ & $3.944,2$ \\
\hline Otros productos químicos..................... & $4.014,9$ & $4.760,9$ & $4.709,0$ & $4.039,7$ & $3.824,7$ & $4.128,9$ & $4.264,0$ & $4.455,4$ \\
\hline Bienes de equipo.................................... & $48.242,8$ & $47.036,6$ & $43.452,5$ & $43.398,6$ & $47.458,3$ & $56.425,3$ & $59.789,0$ & $64.860,6$ \\
\hline Maquinaria agrícola .............................. & 710,8 & 781,7 & 761,6 & 729,4 & 810,0 & 919,6 & 909,4 & 936,8 \\
\hline Maquinaria de obras públicas.............. & 540,1 & 475,9 & 413,9 & 350,8 & 468,7 & 567,7 & 590,2 & 710,5 \\
\hline 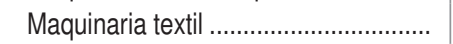 & 265,0 & 180,9 & 218,5 & 193,3 & 264,2 & 321,2 & 273,8 & 253,0 \\
\hline Maquinaria para trabajar metal........... & 549,4 & 640,5 & 615,2 & 647,3 & 752,2 & 854,1 & 957,0 & $1.000,3$ \\
\hline Otra maquinaria específica................... & $1.476,0$ & $1.511,6$ & $1.347,8$ & $1.471,0$ & $1.578,4$ & $1.917,5$ & $2.183,7$ & $2.229,6$ \\
\hline Maquinaria de uso general ................. & $8.363,3$ & $8.569,0$ & $8.221,4$ & $7.985,4$ & $8.983,5$ & $10.440,7$ & $10.964,8$ & $11.678,4$ \\
\hline
\end{tabular}


3.2. COMERCIO EXTERIOR DE MERCANCÍAS. IMPORTACIONES (continuación) DESGLOSE POR SECTORES ECONÓMICOS

(Millones de euros)

\begin{tabular}{|c|c|c|c|c|c|c|c|c|}
\hline & 2010 & 2011 & 2012 & 2013 & 2014 & 2015 & 2016 & $2017^{\star}$ \\
\hline 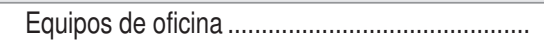 & $1.004,4$ & 859,2 & 891,6 & $1.028,0$ & $1.183,9$ & $1.207,6$ & $1.220,4$ & $1.152,8$ \\
\hline Maquinaria de automatización de datos.............. & $4.010,7$ & $3.470,0$ & $3.373,8$ & $3.326,3$ & $3.475,0$ & $3.762,5$ & $3.640,3$ & $4.261,7$ \\
\hline Equipos telecomunicaciones .............................. & $7.866,4$ & $7.396,1$ & $6.004,3$ & $5.728,5$ & $6.249,2$ & $7.260,4$ & $6.900,5$ & $7.017,9$ \\
\hline Material ferroviario....... & 334,3 & 217,5 & 197,9 & 228,2 & 226,4 & 219,9 & 252,4 & 226,8 \\
\hline Vehic. Trans. mercancías carretera ........................ & $1.516,0$ & $1.762,3$ & $1.354,4$ & $1.609,6$ & $2.173,7$ & $3.179,6$ & $3.563,1$ & $3.694,2$ \\
\hline 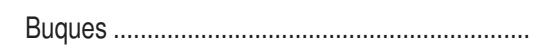 & $1.788,5$ & $1.202,2$ & 995,5 & 171,3 & 253,7 & 234,5 & 314,0 & 685,4 \\
\hline Aeronaves & $2.095,2$ & $1.454,2$ & $1.674,7$ & $2.152,7$ & $1.953,8$ & $2.898,2$ & $3.806,3$ & $5.022,1$ \\
\hline 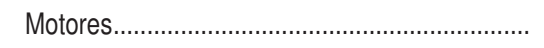 & $1.100,8$ & $1.150,0$ & $1.297,5$ & $1.127,6$ & $1.103,9$ & $1.471,9$ & $1.785,0$ & $2.377,0$ \\
\hline Aparatos eléctricos ............................................ & $8.593,8$ & $9.214,9$ & $8.261,7$ & $8.716,3$ & $9.196,5$ & $10.945,3$ & $11.356,2$ & $12.243,2$ \\
\hline Aparatos de precisión & $3.381,7$ & $3.328,6$ & $3.235,1$ & $3.467,5$ & $3.960,8$ & $4.845,3$ & $5.330,4$ & $5.155,2$ \\
\hline Resto bienes de equipo & $4.646,4$ & $4.821,8$ & $4.587,6$ & $4.465,6$ & $4.824,3$ & $5.379,3$ & $5.741,4$ & $6.215,6$ \\
\hline 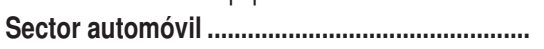 & $24.102,7$ & $27.002,4$ & $23.744,0$ & $25.981,1$ & $30.807,8$ & $35.969,6$ & $37.275,8$ & $39.082,5$ \\
\hline 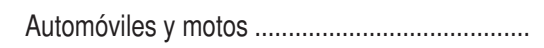 & $9.817,1$ & $10.807,7$ & $8.931,8$ & $9.341,5$ & $12.138,3$ & $15.728,7$ & $17.592,4$ & $19.146,8$ \\
\hline Componentes del automóvil ........... & $14.285,6$ & $16.194,7$ & $14.812,2$ & $16.639,6$ & $18.669,5$ & $20.240,9$ & $19.683,5$ & $19.935,7$ \\
\hline 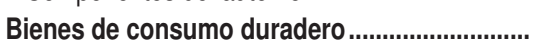 & $8.002,4$ & $6.515,6$ & $5.754,8$ & $5.585,7$ & $6.303,8$ & $7.168,4$ & $7.719,8$ & $8.039,5$ \\
\hline 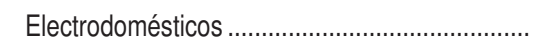 & $1.765,8$ & $1.624,4$ & $1.505,5$ & $1.550,0$ & $1.778,7$ & $2.013,0$ & $2.183,5$ & $2.323,3$ \\
\hline Electrónica de consumo & $2.976,6$ & $1.923,6$ & $1.662,6$ & $1.465,9$ & $1.594,9$ & $1.784,6$ & $1.928,7$ & $1.970,8$ \\
\hline 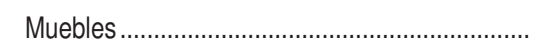 & $2.534,0$ & $2.250,9$ & $1.976,1$ & $1.969,7$ & $2.270,2$ & $2.652,9$ & $2.868,1$ & $2.956,0$ \\
\hline 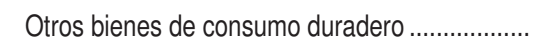 & 726,1 & 716,7 & 610,5 & 600,2 & 660,0 & 717,9 & 739,6 & 789,3 \\
\hline Manufacturas de consumo & $25.801,6$ & $26.859,5$ & $25.904,3$ & $25.818,0$ & $29.416,8$ & $32.793,2$ & $35.078,0$ & $36.578,2$ \\
\hline 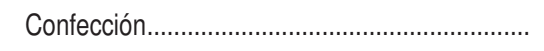 & $10.598,7$ & $11.389,8$ & $11.422,5$ & $11.398,9$ & $12.973,8$ & $14.773,9$ & $15.957,2$ & $16.571,1$ \\
\hline 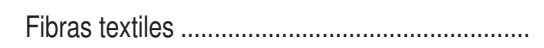 & 279,9 & 307,9 & 266,2 & 373,8 & 393,6 & 399,6 & 410,7 & 439,0 \\
\hline Hilados & 553,1 & 620,2 & 548,4 & 562,4 & 619,5 & 600,8 & 601,2 & 633,9 \\
\hline 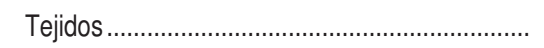 & $1.152,0$ & $1.180,6$ & $1.179,1$ & $1.199,0$ & $1.311,5$ & $1.392,4$ & $1.503,1$ & $1.528,2$ \\
\hline 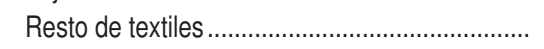 & $1.443,8$ & $1.483,3$ & $1.375,9$ & $1.464,1$ & $1.660,7$ & $1.914,4$ & $2.039,9$ & $2.068,3$ \\
\hline 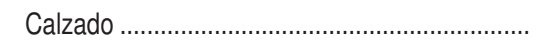 & $2.219,6$ & $2.264,8$ & $2.192,4$ & $2.185,7$ & $2.541,5$ & $2.822,0$ & $3.000,8$ & $3.122,9$ \\
\hline Juguetes & $1.893,2$ & $1.735,8$ & $1.567,5$ & $1.528,0$ & $1.787,3$ & $2.062,3$ & $2.461,9$ & $3.081,3$ \\
\hline Alfarería & 141,6 & 132,6 & 116,7 & 109,9 & 126,2 & 141,4 & 147,3 & 153,4 \\
\hline Joyería y relojes & $1.072,9$ & $1.084,0$ & $1.106,3$ & $1.081,1$ & $1.190,8$ & $1.398,5$ & $1.341,1$ & $1.309,2$ \\
\hline 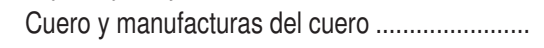 & 455,4 & 579,5 & 534,9 & 585,7 & 693,8 & 600,3 & 558,3 & 552,3 \\
\hline Resto de otras manufacturas de consumo......... & $5.991,4$ & $6.081,0$ & $5.594,3$ & $5.329,4$ & $6.118,1$ & $6.687,6$ & $7.056,5$ & $7.118,6$ \\
\hline Otras mercancías & $1.154,2$ & $1.967,7$ & $2.196,4$ & 890,8 & 663,7 & $1.007,2$ & $1.227,8$ & $1.095,0$ \\
\hline
\end{tabular}

